\title{
Social Cultural and Economic Factors Affecting the Practice of Secondary Prevention among Patients with Type 2 Diabetes Mellitus at Consolata Nkubu and Meru Level Five Hospital in Meru County
}

\author{
Dennis Mugambi Ngari, Annastacia Munzi Mbisi, Teresia Wanjiru Njogu \\ Nursing of Chuka University, Chuka, Kenya \\ Email: dennisngare@gmail.com, annahmbisi@gmail.com,njogu.teresia@yahoo.com
}

How to cite this paper: Ngari, D.M., Mbisi, A.M. and Njogu, T.W. (2020) Social Cultural and Economic Factors Affecting the Practice of Secondary Prevention among Patients with Type 2 Diabetes Mellitus at Consolata Nkubu and Meru Level Five Hospital in Meru County. Open Journal of Clinical Diagnostics, 10, 1-17.

https://doi.org/10.4236/ojcd.2020.101001

Received: December 9, 2019

Accepted: January 28, 2020

Published: January 31, 2020

Copyright $\odot 2020$ by author(s) and Scientific Research Publishing Inc. This work is licensed under the Creative Commons Attribution International License (CC BY 4.0).

http://creativecommons.org/licenses/by/4.0/

\begin{abstract}
Diabetes is chronic metabolic disorder characterized by states of hyperglycemia with disturbances of carbohydrates, fat and protein metabolism. Diabetes affects millions of people globally every day and the prevalence of the disease is on the rise due to unhealthy diet and lifestyle. The disorder usually results to chronic complications including cardiovascular diseases, diabetic nephropathy, diabetic neuropathy, foot ulcers and diabetic eye diseases that are all preventable through secondary preventive measures. Once an individual has been diagnosed with $\mathrm{T}_{2} \mathrm{DM}$, secondary preventive approaches are essential in preventing the occurrence of chronic complications. However, lack of awareness of these measures has been cited as the common reasons for the development of complications. The study aimed to assess the effect of social cultural and economic factors on the practice of secondary diabetes prevention among patients with Type 2 Diabetes Mellitus (T2DM) at Consolata Hospital Nkubu and Meru Level Five Hospital between March and April 2019. A descriptive correlational study design was adopted to collect data from 357 purposively sampled participants with $\mathrm{T}_{2} \mathrm{DM}$ using questionnaires and Focus Group Discussion Guide. Quantitative data were analyzed using SPSS version 25 at $95 \%$ confidence interval and a significance level $p \leq 0.05$. Most respondents attended Meru Teaching and Referral Hospital. Majority of the respondents were aged between 40 - 60 years. Most respondents $31.6 \%$ had secondary level of education and majority $67 \%$ was employed. Concerning secondary prevention, majority did foot examination on every visit $70.6 \%$ and BP monitoring $69.5 \%$ while $56.5 \%$ did annual eye screening. Level of income, affordability of services, health insurance cover of the patients, monthly cost
\end{abstract}


of DM management and traditional beliefs in managing DM all significantly influenced DM secondary prevention at a $\mathrm{p}$ value $\leq 0.05$. The factors need to be addressed to reduce the global burden posed by the disease.

\section{Keywords}

Type 2 Diabetes Mellitus, Secondary Prevention, Economic Factors, Cultural Factors, Chronic Complications

\section{Introduction}

Diabetes mellitus (DM) is a chronic metabolic disorder of multiple etiologies characterized by chronic hyperglycemia with disturbances of carbohydrates, fat and protein metabolism resulting from defects in insulin secretion, insulin action or both [1]. The condition is one of the most significant public health challenges of the 21st century. Diabetes mellitus is among the chronic conditions taking a huge toll on human health and resources, and continue to be neglected by states, individuals, and communities [2]. There are two types of diabetes mellitus: Type1 Diabetes Mellitus (DM) and type 2 diabetes mellitus. Type 1 diabetes mellitus (also referred to as juvenile diabetes) accounts for 5\% - 10\% of diabetes mellitus cases while type 2 DM (maturity-onset diabetes mellitus) accounts for $90 \%-95 \%$ of DM cases [3]. The current trends of DM indicate a disproportionate rise in the prevalence rate in developing nations due to changes in demographic transitions from the traditional to the westernized urban lifestyle. A decade ago, the disease was not considered as a significant public health threat in the developing countries like Kenya, but recently the situation has drastically changed [4]. Currently, Diabetes mellitus has become an epidemic globally that is associated with significant disability, premature deaths and enormous medical costs often resulting from the chronic complications [5].

Diabetes mellitus is characterized by elevated sugar levels in the blood and in urine. A fasting glucose level of $7.0-\mathrm{mmol} / \mathrm{L}$ or higher suggests presence of diabetes mellitus. As well random glucose levels of $11.0-\mathrm{mmol} / \mathrm{L}$ indicate the presence of DM [6]. Uncontrolled DM significantly increases risks of heart diseases, diabetic neuropathy, foot ulcers, kidney failures and diabetic eye diseases (glaucoma, cataract and retinopathy) which are chronic complications of DM. According to an observational research that involved 1746 respondents with type 1 DM and 272 respondents with type $2 \mathrm{DM}$ with their onset being individuals who were younger than 20 years, it was evident from the findings that the prevalence of diabetic retinopathy, kidney disease, and neuropathy was significantly greater in patients with type $2 \mathrm{DM}[7]$.

According to the current posting on the website of the WHO, the worldwide prevalence of diabetes mellitus among persons 18 years of age or older is $8.5 \%$ and increasing [3]. Most of those patients affected by type 2 diabetes have been epidemic for several decades and is associated with many complications, in- 
cluding premature macrovascular and microvascular diseases affecting the eyes, heart, kidneys, and the circulation. Diabetes is associated with major morbidity and mortality, with an estimated 1.5 million deaths in 2012 being directly due to diabetes [8].

Effective interventions are available for lowering the blood glucose levels for diabetic patients thus, delaying the onset of overt diabetes [9]. T2DM is associated with an array of serious health problems. It is a significant risk factor for the development of CVD such as coronary artery disease and stroke [10]. DM is also the leading cause of blindness due to diabetes retinopathy, kidney failure, as well as non-traumatic amputations of the lower limbs [11]. The prevention approaches for DM just like any other chronic disease can be categorized in four stages that are primordial prevention strategies, primary and secondary prevention and tertiary prevention strategies [12]. Secondary prevention refers to preventing complications in those who already have diabetes with the aim of delaying or preventing the development of long-term complications of the disease such as DR, diabetes neuropathy and cardiovascular complications [13].

The burden of T2DM complications and comorbidity is substantial among sub-Saharan Africans (SSA). Interventions to reduce T2DM morbidity and mortality in SSA need to prioritize early detection, the maintenance of healthy blood pressure, weight and lipid levels, as well as strengthen health care system capacities to provide treatment and care for neurological and ophthalmological complications of T2DM [14]. Chronic complications of diabetes mellitus can be effectively controlled through the diabetic secondary preventive measures that include eye examinations, cardiovascular care, kidney care and foot care. However, these services are underutilized due to inadequate knowledge by the patients coupled with other influencing factors that include social-cultural and economic factors [15]. Thus, the study aimed at assessing the social cultural and economic factors affecting the practice of secondary diabetes prevention among patients with Type 2 Diabetes Mellitus (T2DM) at Consolata Hospital Nkubu and Meru Level Five Hospitals.

\section{Methodology}

The study was conducted at Consolata Hospital Nkubu and Meru Level Five Hospital in Meru County between March and April 2019. Meru Level Five Hospital is a public hospital located in Miriga Mieru East Division, North Imenti Constituency in Meru County while Consolata Hospital Nkubu is a private hospital located in Kathera Sub-location Nkuene location, Nkuene Division, South Imenti Constituency Meru County. The facilities offer both basic and emergency care including diabetic care services thus suitable for the research study. The diabetic services offered include diabetes screening, diabetes treatment, diabetes counseling including methods of preventing diabetes complications such as foot care, cardiovascular screening, nephropathy screening and eye care.

A descriptive correlational study design was employed to assess the effect of 
social cultural and economic factors on the practice of secondary diabetes prevention among the patients with type 2 diabetes mellitus at Consolata Nkubu and Meru Level Five Hospital in Meru County. This study included 357 adult patients with the diagnosis of diabetes mellitus type II attending diabetic clinics at the facility. Diabetes secondary prevention practices assed in the study include: Blood pressure monitoring, patient's eye screening, albumin urine check, cholesterol level check-up as well as foot examinations for foot ulcers. These practices are paramount in the prevention of chronic complications of diabetes. The study included adult patients with T2DM attending diabetic clinics who were willing to participate in the study.

Purposive sampling method was used to sample type 2 DM patients in both hospitals. Stratified sampling was then used to get both representation of men and women in the study. Simple random sampling was then used to get the actual respondents as they attended diabetic clinic. The trained interviewer administered the questionnaires to the patients as they attended their diabetic clinic for a period of two months until the desired sample size was attained which was determined using fisher et al. (1998) [16] and Cochran's formula (1963) [17]. The questionnaire assessed whether the Level of income, affordability of services, health insurance cover of the patients, monthly cost of DM management and traditional beliefs influenced diabetes secondary prevention.

Permission to conduct this study was obtained from National Commission for Science, Technology and Innovation (NACOSTI) through the Chuka University Ethics and Research Committee for review and approval. Permission was also sought from Consolata Hospital Nkubu and Meru Level Five Hospital before commencement of data collection. The main ethical issues addressed in the research included ensuring privacy and confidentiality during data collection. Informed consent was also obtained from the respondents where they were informed to fill an informed consent form as prove of their acceptance and availability to participate in the study. Names of subjects were kept anonymous by writing their unique codes on the questionnaire instead of their names. Data was cleaned, coded and analyzed at a significance $\mathrm{p} \leq 0.05$. Frequencies and percentages were used to describe the quantitative data. Chi squares was used to test the relationship between variables of association at $95 \%$ significance level.

\section{Results}

Table 1 presents the demographic characteristics of the respondents.

Table 1 shows that 189 (53.4\%) were seeking treatment at Meru hospital while $165(46.6 \%)$ were being treated at Consolata Nkubu Hospital. Six respondents i.e. $6(1.7 \%)$ were aged below 40, 104 (29.4\%) were aged 40 - 50, 105 (29.7\%) were aged $51-60,72(20.3 \%)$ were aged between 61 - 70 years, 55 (15.5\%) were aged $71-80$ and $12(3.4 \%)$ were aged above 80 years.

Most respondents i.e. 178 (50.3\%) were males while 176 (49.7\%) were females. 
Table 1. Demographic characteristics of the respondents.

\begin{tabular}{|c|c|c|}
\hline Characteristic & Frequency (n) & Percentage (\%) \\
\hline \multicolumn{3}{|l|}{ Facility } \\
\hline Meru Level 5 Hospital & 189 & 53.4 \\
\hline Consolata Nkubu Hospital & 165 & 46.6 \\
\hline Total & 354 & 100 \\
\hline \multicolumn{3}{|l|}{ Age in years } \\
\hline Below 40 & 6 & 1.7 \\
\hline $40-50$ & 104 & 29.4 \\
\hline $51-60$ & 105 & 29.7 \\
\hline $61-70$ & 72 & 20.3 \\
\hline $71-80$ & 55 & 15.5 \\
\hline Above 80 & 12 & 3.4 \\
\hline Total & 354 & 100 \\
\hline \multicolumn{3}{|l|}{ Gender } \\
\hline Male & 178 & 50.3 \\
\hline Female & 176 & 49.7 \\
\hline Total & 354 & 100 \\
\hline \multicolumn{3}{|l|}{ Level of Education } \\
\hline No formal education & 66 & 18.6 \\
\hline Primary & 68 & 19.2 \\
\hline Secondary & 112 & 31.6 \\
\hline College & 108 & 30.5 \\
\hline Total & 354 & 100 \\
\hline \multicolumn{3}{|l|}{ Occupation } \\
\hline Employed & 92 & 26 \\
\hline Self-employed & 146 & 41.2 \\
\hline Not employed & 116 & 32.8 \\
\hline Total & 354 & 100 \\
\hline \multicolumn{3}{|l|}{ Marital status } \\
\hline Single & 17 & 4.8 \\
\hline Married & 197 & 55.6 \\
\hline Separated & 42 & 11.9 \\
\hline Divorced & 19 & 5.4 \\
\hline Widowed & 79 & 22.3 \\
\hline Total & 354 & 100 \\
\hline \multicolumn{3}{|l|}{ Occupation of spouse } \\
\hline Employed & 75 & 21.2 \\
\hline Self-employed & 85 & 24 \\
\hline Not employed & 36 & 10.2 \\
\hline Not applicable & 158 & 44.6 \\
\hline Total & 354 & 100 \\
\hline \multicolumn{3}{|l|}{ Spouse education level } \\
\hline No formal education & 6 & 1.7 \\
\hline Primary & 46 & 13 \\
\hline Secondary & 70 & 19.8 \\
\hline College & 74 & 20.9 \\
\hline Not applicable & 158 & 44.6 \\
\hline Total & 354 & 100 \\
\hline
\end{tabular}


Sixty six respondents (18.6\%) had no formal education, 68 (19.2\%) had primary level of education, 112 (31.6\%) had secondary education level and 108 (30.5\%) had college level of education. Ninety two respondents i.e. $26 \%$ were employed, 146 (41.2\%) were self-employed, and 116 (32.8\%) were not employed. Concerning marital statuses, 17 (4.8\%) were single, 197 (55.6\%) were married, 42 (11.9\%) were separated, 19(5.4\%) were divorced and 79 (22.3\%) were widowed.

Concerning the spouses' occupations, 75 (21.2\%) were employed, 85 (24\%) were self-employed, and 36 (10.2\%) were not employed. In terms of education, 6 (1.7\%) had no formal education, 46 (13\%) had primary level, $70(19.8 \%)$ had secondary education and 74 (20.9\%) had college level of education.

\section{Secondary preventive measures practiced among patients}

The patients reported to practice varied secondary preventive measures as shown in Table 2.

Table 2 shows that $70.6 \%(\mathrm{n}=250)$ of the respondents did foot examination during every visit to the clinic, $56.5 \%(\mathrm{n}=200)$ had their eyes examined annually, 26\% ( $\mathrm{n}=92)$ had urine checks annually, 18.9\% $(\mathrm{n}=67)$ had body cholesterol level check-up regularly and $69.5 \%(n=246)$ had regular blood pressure monitoring. The mean score was $48.3 \%$ and $\mathrm{SD}$ was 30.1

\section{Criterion on Level of practice of secondary preventive measures}

The level of practice was determined by the number of practice items that respondents adhered to as described on Table 2. Those respondents who adhered to at least three items were considered to have good secondary prevention practice while those who adhered to less than three were considered to have poor secondary prevention practice.

Figure 1 shows that $45.5 \%$ (161) had good secondary prevention practice while $54.5 \%$ (193) had poor secondary prevention practice. The level of practice was the dependent variable in this study and all independent variables were cross-tabulated against it to check for any statistical significance.

Economic and Social Cultural Factors Influencing DM Secondary Prevention

The economic and socio-cultural factors under investigation included level of income, affordability of services, health insurance cover, and monthly cost of DM management, traditional beliefs and myths in the society.

\section{Level of income and DM secondary prevention}

The level of income was categorized into three categories; this was done after

Table 2. Diabetic secondary preventive practices of the respondents.

\begin{tabular}{cc}
\hline Practice item & Correct practice (\%) \\
\hline Foot examination every visit & $70.6 \%$ \\
Eye screening annually & $56.5 \%$ \\
Urine check-up annually for albumin & $26 \%$ \\
Body cholesterol level check-up & $18.9 \%$ \\
Blood pressure monitoring & $69.5 \%$ \\
\hline
\end{tabular}


collecting data in which the patients had reported specific monthly income. The respondents had indicated the lowest level of income to be Kshs. 3000 and the highest had an income of Kshs. 42,000. This was categorized for easy analysis.

Figure 2 shows that $43.5 \%(\mathrm{n}=154)$ earned above $15,000,27.4 \%(\mathrm{n}=97)$ earned between $5001-15,000$ shillings while $29.1 \%(n=103)$ earned less than 5000 Kenya shillings per month.

The researcher further categorized the income as above Kshs 15,000 and below Kshs. 15,000. This was used to carry out binary regression analysis between level of income and practice of secondary preventive measures. The results are shown in Table 3.

Table 3 shows that the level of monthly income significantly affected DM secondary prevention $\left(\chi^{2}(1, \mathrm{~N}=354)=66.79, \mathrm{p} \leq 0.001, \mathrm{OR}=0.154\right)$ whereby,

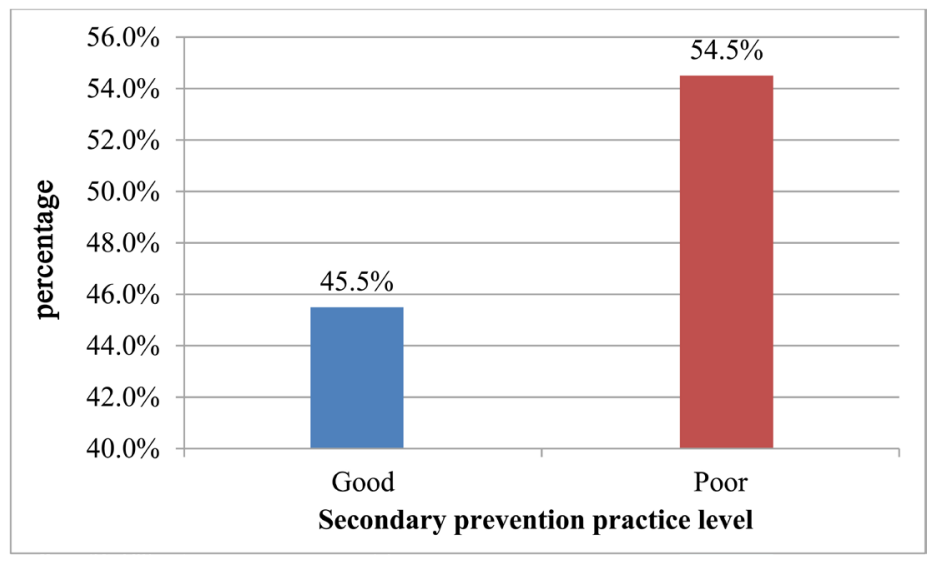

Figure 1. Practice level of secondary preventive measures for Diabetic complication.

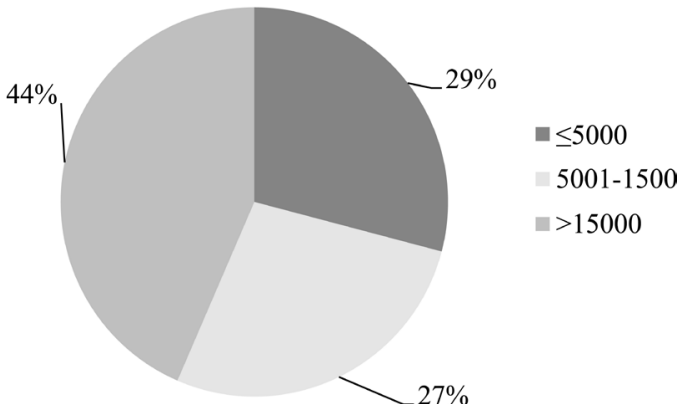

Figure 2. Income levels of respondents.

Table 3. Association between monthly income and practice of secondary preventive measures for DM complications

\begin{tabular}{ccccc}
\hline & & \multicolumn{2}{c}{ What is your level of monthly income? } & \multirow{2}{*}{ Total } \\
\cline { 3 - 4 } & & 15,000 and below & Above 15,000 & \\
\hline $\begin{array}{c}\text { DM complications secondary } \\
\text { prevention practice }\end{array}$ & Good & 53 & 108 & 161 \\
Total & Poor & 147 & 46 & 193 \\
& & 200 & 154 & 354 \\
\hline
\end{tabular}

$\chi^{2}(1, \mathrm{~N}=354)=66.794, \mathrm{p} \leq 0.001$. 
those earning 15,000 or less were less likely to practice secondary prevention.

\section{Affordability of services and DM secondary prevention}

Majority i.e. $77.1 \%(\mathrm{n}=273)$ reported that DM services were affordable while $22.9 \%(n=81)$ reported that they were not.

Table 4 shows that affordability of services significantly influenced DM secondary prevention practice $\left(\chi^{2}(1, \mathrm{~N}=354)=61.40, \mathrm{p} \leq 0.001, \mathrm{OR}=16.419\right.$ whereby, those who reported that services were affordable were 16 times more likely to practice secondary prevention.

\section{Health insurance cover and DM secondary prevention}

Some health insurance covers were catering for all the expenses for diabetic management while others were not. This made the researcher to identify and establish the health insurance cover each respondent had. The results are tabulated in Figure 3.

Figure 3 shows that majority of the respondents i.e. $68.4 \%(\mathrm{n}=242)$ were members of NHIF, 3.7\% $(n=13)$ had company insurance cover, $4.2 \%(n=15)$ had both NHIF and company insurance, $2.5 \%(\mathrm{n}=9)$ had Kinga ya mkulima while $21.2 \%(n=75)$ had no health insurance cover at all.

However it emerged from the results that some patients had health insurance covers regardless of which while others never had the health insurance cover. The researcher computed a Chi-squaire between having or not having a health insurance cover and practice of secondary preventive measures in diabetic management.

Table 4. Association between affordability of services and practice of secondary preventive measures for DM complications.

\begin{tabular}{ccccc}
\hline & & \multicolumn{2}{c}{ Are the services affordable? } & \multirow{2}{*}{ Total } \\
\cline { 3 - 4 } & & Yes & No & \\
\hline \multirow{2}{*}{$\begin{array}{c}\text { DM complications secondary } \\
\text { prevention practice }\end{array}$} & Good & 155 & 6 & 161 \\
Total & Poor & 118 & 75 & 193 \\
& & 273 & 81 & 354 \\
\hline
\end{tabular}

$\chi^{2}(1, \mathrm{~N}=354)=61.402, \mathrm{p} \leq 0.001$.

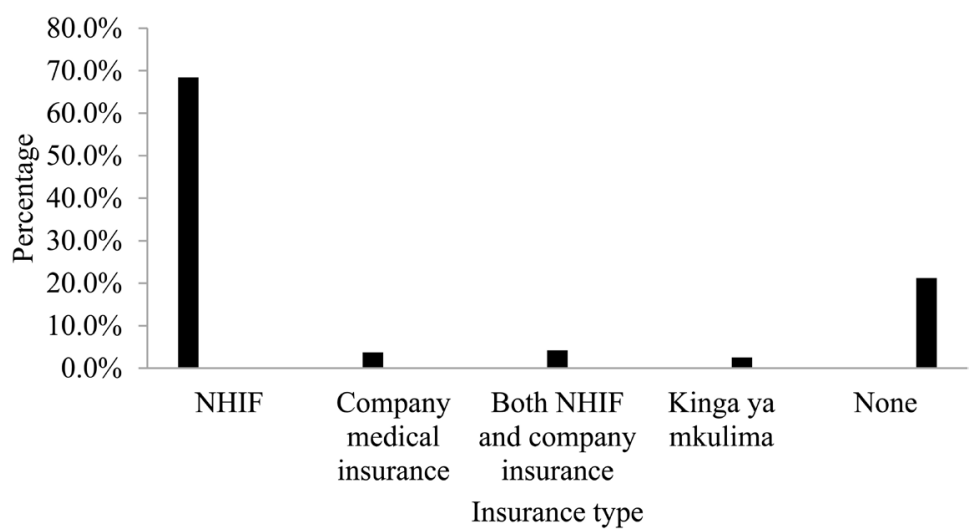

Figure 3. Types of insurance covers for the respondents. 
Table 5 shows that availability of health insurance cover influenced practice of DM secondary prevention $\left(\chi^{2}(1, \mathrm{~N}=354)=46.51, \mathrm{p} \leq 0.001, \mathrm{OR}=10.17\right)$ whereby, those who had some form of health insurance cover were 10 more times likely to practice secondary prevention.

\section{Monthly cost of DM management and secondary prevention}

Figure 4 shows that $68.6 \%(\mathrm{n}=243)$ spent less 5000 shillings in DM management, $29.4 \%(\mathrm{n}=104)$ spent 15,000 and below while $2 \%(\mathrm{n}=7)$ spent over 15,000 shillings.

Table 6 shows that the estimated cost of DM management significantly influenced secondary prevention $\left(\chi^{2}(1, \mathrm{~N}=354)=35.78, \mathrm{p} \leq 0.001\right.$, $\left.\mathrm{OR}=0.242\right)$ whereby, those who estimated the monthly costs to be 5000 or less were less likely to practice secondary prevention.

Table 5. Association between health insurance cover for the respondent and practice of secondary preventive measures for DM complications.

\begin{tabular}{ccccc}
\hline & & \multicolumn{2}{c}{ Do you have any health insurance cover? } & \multirow{2}{*}{ Total } \\
\cline { 3 - 4 } & & Yes & No & \\
\hline $\begin{array}{c}\text { DM complications secondary } \\
\text { prevention practice }\end{array}$ & Good & 153 & 8 & 161 \\
Total & Poor & 126 & 67 & 193 \\
\hline
\end{tabular}

$\chi^{2}(1, \mathrm{~N}=354)=46.514, \mathrm{p} \leq 0.001$.

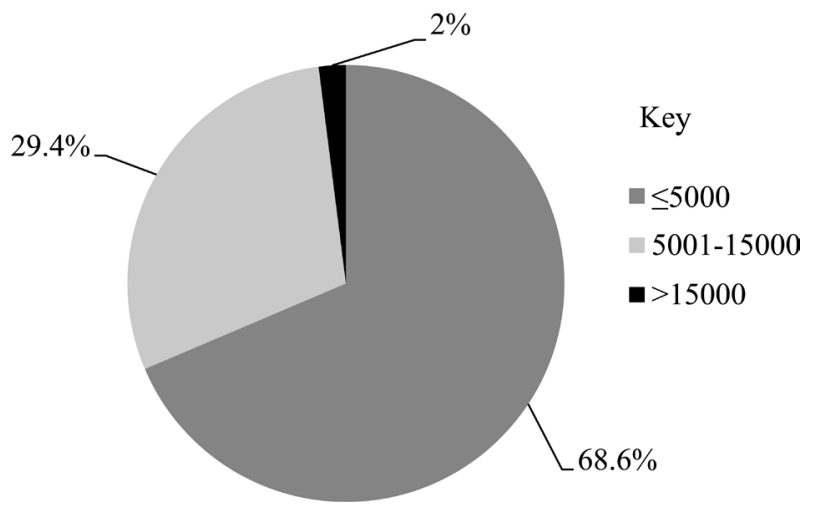

Figure 4. Estimated monthly DM costs for respondents.

Table 6. Association between estimated DM management costs and practice of secondary preventive measures for DM complications.

\begin{tabular}{ccccc}
\hline & & \multicolumn{2}{c}{$\begin{array}{c}\text { What is your estimated general cost of } \\
\text { diabetes management per month? }\end{array}$} & Total \\
\cline { 3 - 4 } & & 5000 and below & Above 5000 & \\
\hline $\begin{array}{c}\text { DM complications secondary } \\
\text { prevention practice }\end{array}$ & Good & 84 & 77 & 161 \\
Total & & 158 & 35 & 354 \\
\hline
\end{tabular}

$\chi^{2}(1, \mathrm{~N}=354)=35.778, \mathrm{p} \leq 0.001$. 


\section{Cultural and traditional beliefs/myths and DM secondary prevention}

Few respondents i.e. $27.1 \%(\mathrm{n}=96)$ reported that there were cultural and traditional beliefs that could potentially hinder utilization of diabetes services, while $72.9 \%(\mathrm{n}=258)$ reported that such beliefs did not exist. The main traditional beliefs/myths were summarized as follows:

\section{Diabetes etiology and management}

Some respondents $10.2 \%(n=36)$ believed that diabetes was associated with curses and witchcraft and that one with DM ulcer was bewitched. As such, remedies such as prayers, witchcraft, traditional healers and herbal medicine could cure DM. When one had hyperglycemia, bitter herbs were very effective in lowering the blood sugars. DM patients should not eat sugary things because sugar levels would go high and easily accessible foods e.g. potatoes and cassava were restricted. There was no need of attempting to spend money to manage a lifelong disease whose management was too expensive. People did not die as a result of DM but rather from the harmful effects of the drugs they took. DM drugs made people grow fat and others ended up becoming obese. Women of childbearing age for instance should not take drugs, because these drugs ended up affecting their unborn children. During blood glucose monitoring, the pricking of fingers led to loss of too much blood and patients could die of anemia. Others believed that DM drugs should be taken for a short time because the disease was curable.

\section{Diabetes epidemiology}

Diabetes is preserved only for fat people, the elderly and the rich; this was suggested by majority of the respondents $5.1 \%(n=18)$. It affects more males than females; this was reported by $2.8 \%(\mathrm{n}=10)$. Therefore, the young and the slim could rest assured that whatever they might be suffering from could not in any way be diabetes.

\section{The rights of women}

Women couldn't go anywhere unless accompanied by their husbands. Men had a big say in the family and major decisions especially those touching on the health of women came from men; this was indicated by $9 \%(n=32)$. If the man was not in a position to accompany the wife to clinic, the wife would rather wait until it was convenient for the husband.

Table 7 shows that cultural and traditional beliefs/myths significantly influenced

Table 7. Association between traditional beliefs/myths and secondary prevention measures for DM complications.

\begin{tabular}{ccccc}
\hline & & \multicolumn{2}{c}{$\begin{array}{c}\text { Are there cultural and traditional beliefs } \\
\text { that hinder utilization of diabetic services? }\end{array}$} & \multirow{2}{*}{ Total } \\
\cline { 3 - 4 } & & Yes & No & \\
\hline DM complications secondary & Good & 28 & 133 & 161 \\
prevention practice & Poor & 68 & 125 & 193 \\
Total & & 96 & 258 & 354 \\
\hline
\end{tabular}

$\chi^{2}(1, \mathrm{~N}=354)=14.138, \mathrm{p} \leq 0.001$. 
DM secondary prevention practice $\left(\chi^{2}(1, \mathrm{~N}=354)=14.14, \mathrm{p} \leq 0.001, \mathrm{OR}=\right.$ $0.387)$ whereby, those who reported the existence of traditional beliefs were less likely to practice secondary prevention.

The results from the research show that various social, economic and traditional beliefs had a statistically significant association with the practice of secondary preventive practices among T2DM patients.

Results as captured on Appendix I and Appendix II.

\section{Discussion}

The income of the respondents was significantly affecting the practice of secondary preventive measures for diabetic complications. Those who earned more were found to practice the secondary preventive measures than those who earned less, or were poor. These results are in agreement with those reported in the city of Isfahan. In Isfahan, the patients' economic status was found to determine the services the patients received in the hospital. Those patients who were economically stable received all screening tests for diabetic complications [18]. In another study, patients who belonged to low social economic status were linked to have more T2DM complications [19]. Similar findings were shown in a study in Thailand, where patients with low socio economic status were associated with complications of diabetes mellitus [20]. However, the patient individual income was found not to determine the diabetic complications in China where there was no association between patient's economic status and development of diabetic complications [21].

Affordability was a key indicator of the practices; those patients who were affording the cost of screening tests were more often screened compared to those who were unable to afford the screening tests. These results concur with those revealed in Korea on socioeconomic status of patients on their health behaviors, metabolic control, and chronic complications in T2DM. It was revealed that women with lower income were associated with higher stress level. This increased the chances of developing diabetic retinopathy [22] [23]. In the United Kingdom, low social and economic status were linked with high rates of death and morbidity as a result of diabetic related complications [24].

The patients who had the National Health Insurance Fund (NHIF) cover were more likely to receive the screening test compared to those who had other insurance covers. In this study the insurance cover that a patient had, was associated with the practice of secondary preventive measures. In China, it was also found that different respondents had different insurance covers; each cover had limited range of services to cover. This was associated with management of diabetes type 2 [11]. Another research done in Germany revealed that the cost of diabetes management differed between age groups and insurance cover for all that helped cut the costs [25].

The management cost for screening tests was high. Those patients whose screening tests cost was covered by the insurance scheme, were more likely to 
practice secondary preventive measures than those whose insurance scheme was not covering the screening tests. Patients from low socioeconomic status need to be catered for in terms of drug costs, this helps in the maintenance of glycemic levels within normal ranges. They should be screened for stress and depression. This was found to be associated with preventive measures for diabetes complications [26].

There were some patients who believed in traditional healing methods for diabetes. Others had myths about the diabetes disease; some believed it was a curse and others believed it was witchcraft. Those patients who believed in the medical pathology of diabetes, and that diabetes can be modified were more likely to practice secondary preventive measures for diabetic complications. In Chicago, diabetic patients had a negative perception about insulin use in management of the disease. Inaccurate information about complications of insulin in Diabetes management led to the negative perceptions [27]. Some religious beliefs, especially on fasting occasions affect both positively and negatively on management of diabetes. In Lamu town, ritual obligations observed especially while attending wedding ceremonies which last for weeks affect the management of diabetes. These occasions affected dietary restrictions of the diabetic patients [28]. The results in this study revealed that in this era, some patients still belief in herbal remedies for treatment and management of diabetes, these results concur with those found in a study in South Asia. In South Asia, patients with diabetic and cardiovascular diseases were found to prefer use of home remedies and poorly sought health care services from the hospital [29].

\section{Conclusion}

The main socio-economic factors that affected secondary prevention were: level of income, patients' type of insurance cover, management cost per for diabetes, traditional beliefs about the cause and management of diabetes and affordability of services.

\section{Study Limitations}

The limitations in this study was the large sample size involved in the study where there was a none-response of 3 respondents from the set sample size of 357 study participants. There was also a language barrier when administering the questionnaire as some respondents could only understand the local native language of "Kimeru".

\section{Recommendations}

1) The government of Kenya, through the county government to champion for campaigns on educating the public on secondary preventive measures for diabetic complications. These will include; retinopathy screening, kidney care and screening, cardiovascular care and screening, as well as foot care and ensuring medical services availability among the diabetic patients. 
2) All the nurses in all facilities in Meru County, to champion for screening tests for both microvascular and macrovascular complications among patients in each clinic that diabetic patients attend.

3) Make services free or cheaper and encourage patient's enrollment in insurance covers to reduce T2DM management cost.

4) Health-educate and remind patients on preventive practices, organize grass root campaigns and seminars for all to promote secondary prevention and dismiss associated beliefs.

\section{Conflicts of Interest}

The authors declare no conflicts of interest regarding the publication of this paper.

\section{References}

[1] International Diabetes Federation (2017) IDF Diabetes Atlas. 10th Edition, IDF, Brussels. http://www.diabetesatlas.org

[2] KDHS (2016) Demographic and Health Surveys. Kenya National Bureau of Statistics, Nairobi.

[3] World Health Organization (2018) Global Report on Diabetes. Diabetes Fact Sheet. https://www.who.int/news-room/fact-sheets/detail/diabetes

[4] Fatema, K., Hossain, S., Natasha, K., Chowdhury, H.A., Akter, J., Khan, T. and Ali, L. (2017) Knowledge Attitude and Practice Regarding Diabetes Mellitus among Nondiabetic and Diabetic Study Participants in Bangladesh. BMC Public Health, 17, Article No. 364. https://doi.org/10.1186/s12889-017-4285-9

[5] World Health Organization (2016) Global Report on Diabetes. World Health Organization, Geneva. http://apps.who.int/iris/bitstream/10665/204871/1/9789241565257 eng.pdf?ua=1

[6] Brunner, L.S. and Smeltzer, S.C.O.C. (2010) Brunner \& Suddarth's Textbook of Medical-Surgical Nursing. Wolters Kluwer Health/Lippincott Williams \& Wilkins, Philadelphia.

[7] Dabelea, D., Jeanette, M., Stafford, M.S., Elizabeth, J., Mayer-Davis, E.J., et al. (2017) Association of Type 1 Diabetes vs. Type 2 Diabetes Diagnosed during Childhood and Adolescence with Complications during Teenage Years and Young Adulthood. $J A M A, 317,825-835$. https://doi.org/10.1001/jama.2017.0686

[8] Ingelfinger, J.R. and Rosen, C.J. (2016) Cardiac and Renovascular Complications in Type 2 Diabetes. The New England Journal of Medicine, 375, 380-382. https://doi.org/10.1056/NEJMe1607413

[9] Bayu, B. (2019) The Prevalence of Macro and Microvascular Complications of DM among Patients in Ethiopia 1990-2017: Systematic Review. Diabetes \& Metabolic Syndrome: Clinical \& Research Reviews Journal, 13, 672-677. https://doi.org/10.1016/j.dsx.2018.11.046

[10] Alaboud, A., Tourkmani, A., Pharm, D., Turki, J., et al. (2016) Microvascular and Macrovascular Complications of Type 2 Diabetic Mellitus in Central, Kingdom of Saudi Arabia. Saudi Medical Journal, 37, 1408-1411. https://doi.org/10.15537/smj.2016.12.17062

[11] Wu, Y., Ding, Y., Tanaka, Y. and Zhang, W. (2014) Risk Factors Contributing to Type 2 Diabetes and Recent Advances in the Treatment and Prevention. Interna- 
tional Journal of Medical Sciences, 11, 1185-1200.

https://doi.org/10.7150/ijms.10001

[12] Psaltopoulou, T., Ilias, I. and Alevizaki, M. (2010) The Role of Diet and Lifestyle in Primary, Secondary, and Tertiary Diabetes Prevention: A Review of Meta-Analyses. The Review of Diabetic Studies, 7, 26-35. https://doi.org/10.1900/RDS.2010.7.26

[13] Ahmad, L.A. and Crandall, J.P. (2010) Type 2 Diabetes Prevention: A Review. Clinical Diabetes, 28, 53-59. https://doi.org/10.2337/diaclin.28.2.53

[14] Ekoru, K. and Doumatery, A. (2019) Prevalence and Risk Factors for Type 2 Diabetes Complications and Comorbidity in Sub-Saharan Africans.

[15] Rahaman, K.S., Majdzadeh, R., Naieni, K.H. and Raza, O. (2017) Knowledge, Attitude and Practices (KAP) Regarding Chronic Complications of Diabetes among Patients with Type 2 Diabetes in Dhaka. International Journal of Endocrinology and Metabolism, 15, e12555. https://doi.org/10.5812/ijem.12555

[16] Fisher, A.A., Laing, J.E., Stoeckel, J.E. and Townsend, J.W. (1998) Handbook for Family Planning Operations Research Design. Second Edition, Population Council, New York.

[17] Cochran, W.G. (1963) Sampling Techniques. 2nd Edition, John Wiley and Sons, Inc., New York.

[18] Tol, A., Sharifirad, G., Shojaezadeh, D., Tavasoli, E. and Azadbakht, L. (2013) Socio-Economic Factors and Diabetic Consequences among Patients with Type 2 Diabetes. Journal of Education and Health Promotion, 2, 12. https://doi.org/10.4103/2277-9531.108009

[19] Funakoshi, M., Azami, Y., Matsumoto, H., Ikota, A., Ito, K., et al. (2017) Socioeconomic Status and Type 2 Diabetes Complications among Young Adult Patients in Japan. PLoS ONE, 12, e0176087. https://doi.org/10.1371/journal.pone.0176087

[20] Suwannaphant, K., Laohasiriwong, W., Puttanapong, N., Saengsuwan, J. and Phajan, T. (2017) Association between Socioeconomic Status and Diabetes Mellitus: The National Socioeconomic Survey, 2010 and 2012. Journal of Clinical and Diagnostic Research, 11, LC18-LC22. https://doi.org/10.7860/JCDR/2017/28221.10286

[21] Emoto, N., Okajima, F., Sugihara, H. and Goto, R. (2016) A Socioeconomic and Behavioural Survey of Patients with Difficult-to-Control Type 2 Diabetes Mellitus Reveals an Association between Diabetic Retinopathy and Educational Attainment. Patient Prevalence and Adherence, 10, 2151-2162. https://doi.org/10.2147/PPA.S116198

[22] Kim, S., Lee, S., Kim, C., Suh, Y., Hong, S., Ahn, S., Nam, M. and Kim, Y. (2018) Impact of Socioeconomic Status on Health Behaviors, Metabolic Control, and Chronic Complications in Type 2 Diabetes Mellitus. Diabetes \& Metabolism Journal, 42, 380-393. https://doi.org/10.4093/dmj.2017.0102

[23] Peykari, N., Djalalinia, S., Qorbani, M., Sobhani, S., Bagher, L. and Farzadfar, F. (2015) Socioeconomic Inequalities and Diabetes: A Systematic Review from Iran. Journal of Diabetes \& Metabolic Disorders, 14, 8. https://doi.org/10.1186/s40200-015-0135-4

[24] Scott, A., Chambers, D., Goyder, E. and Cathain, A. (2017) Socioeconomic Inequalities in Mortality, Morbidity and Diabetes Management for Adults with Type $1 \mathrm{Di}-$ abetes: A Systematic Review. PLoS ONE, 12, e0177210.

https://doi.org/10.1371/journal.pone.0177210

[25] Kahm, K., Laxy, M., Schnelder, U., Wolf, H., Stefan, K., Rolf, H. and Lhachimi (2018) Health Care Costs Associated with Incident Complications in Patients with Type 2 Diabetes in Germany. Diabetes Care, 41, 971-978. 
https://doi.org/10.2337/dc17-1763

[26] Houle, J., Lauzier-Jobin, F., Beaulieu, M.D., et al. (2016) Socioeconomic Status and Glycemic Control in Adult Patients with Type 2 Diabetes: A Mediation Analysis. BMJ Open Diabetes Research \& Care, 4, e000184.

https://doi.org/10.1136/bmjdrc-2015-000184

[27] Julio, A., Rebolledo and Arellano, R. (2015) Cultural Differences and Considerations When Initiating Insulin. Midwestern University, Chicago College of Pharmacy, Downers Grove.

[28] Abdulrehman, M., Woith, W., Sheryl, J., Kossaman, S. and Hunter, G. (2016) Exploring Cultural Influences of Self Management of Diabetes in Coastal Kenya: An Ethnography. Global Qualitative Nursing Research, 3, 1-13.

https://doi.org/10.1177/2333393616641825

[29] Kumar, K., Greenfield, S., Raza, K., Stack, R. and Gill, P. (2016) Understanding Adherence Related Beliefs about Medicine amongst Patients of South Asian Origin with Diabetes and Cardiovascular Disease: Qualitative Synthesis. BMC Endocrine Disorders, 16, Article No. 24. https://doi.org/10.1186/s12902-016-0103-0 


\section{Appendix I. Questionnaire for the Study Participants}

\section{Instructions}

1. Do not write your name.

2. Fill all the relevant sections

3. Use a tick $(\sqrt{ })$ where applicable

Serial No.............

\section{Part A: Demographic Information}

1) Age (Years):

2) Gender: Male [ ] Female [ ]

3) Level of Education
a) No formal education [
b) Primary [ ] ]
c) Secondary [
d) College [ ]

4) Occupation
a) Employed [ ] ]
b) Self-employed [ ]
c) Not employed [ ]

5) Marital status
a) Single [ ]
b) Married [ ]
c) Separated [ ]
d) Divorced [ ]
e) Widowed [ ]

6) If married, spouse occupation
a) Employed [ ] ]
b) Self-employed [ ]
c) Not employed [ ]
d) Not Applicable [ ]

7) Spouse level of education completed
a) No formal education [
b) Primary [ ] ]
c) Secondary [
d) College [
e) Not Applicable [ ]

\section{Part B: The Practice on the Secondary Preventive measures}

8) Which of the following complications is associated with diabetes?
a) Foot ulcers [ ]
b) Nerve problems [
c) Kidney failures [ ]
d) Diabetic eye diseases (diabetic retinopathy, glaucoma and cataract) [
e) Hypertension (Elevated Blood pressure) [ ]
f) Any other (specify).

9) Do you do Foot examinations?
a) Yes [
b) No [

10) How frequent should you go for eye checkup?
a) Yearly [ ]
b) every two years [
]
c) Depend with eye condition [
d) Don't know [ ]

11) Have you ever had eye screening since you were diagnosed with diabetes?
a) Yes [
b) No [

12) Have you ever done a urine check before?
a) Yes [
b) No [

13) How frequent should a person do the urine check?
a) Yearly [
b) every two years [
]
c) Don't know [ ]

14) Do you think diabetic patients should have check-ups on their body's fat levels (Cholesterol)?
a) Yes [
b) No [ ]
c) Don't know [

15) Do you have any check-ups on your body's fat levels?
a) Yes [
b) No 
16) Do have regular check-ups on your blood pressure levels?
a) Yes [
b) No [ ]

\section{Part C: Social Cultural and Economic Factors}

17) What is your level of income in Kenyan shillings?
a) Below or 5000 [ ] ]
b) Between $5001-15,000[\quad]$
c) Above 15,001 [ ]

18) Are the services affordable at the hospital?
a) Yes [ ]
b) No [ ]

19) Do you currently have any health insurance cover?
a) Yes [ ]
b) No [ ]

20) If yes in 2 above, what type?
a) NHIF [ ]
b) Company medical insurance [ ]
c) Both [ ]
d) Any other [ ]

21) What is your estimated general cost on the management of diabetes per month in Kenyan shilling?
a) Below or 5000 [ ] ]
b) Between $5001-15,000$ [
c) Above 15,001 [

22) Can you comfortably take care of the diabetes services costs?
a) Yes [
b) No [ ]

23) Are there cultural and traditional beliefs that hinder the utilization of diabetic services?
a) Yes [
b) No [

24) If Yes in 6 above which ones?

25) Are there Myths in the society that prevent individuals from seeking diabetic care?

26) Do you have a negative attitude towards the secondary preventive services offered?
a) Yes [
b) No [

27) What are some of the measures that you propose to be undertaken to improve the practice of secondary prevention in diabetes management?

\section{Appendix II. Focus Group Discussion Guide}

1. Have you been taught/trained on the special self-care because you are diabetic?

2. What socio-cultural and economic factors encourage you to perform the special care?

3. What socio-cultural and economic factors factors/barriers do you face as you take care of your illness? 